\title{
QUEEN'S
UNIVERSITY
BELFAST
}

\section{Immature platelet fraction as a useful marker in the etiological determination of thrombocytopenia}

Ali, I., Graham, C., \& Dempsey-Hibbert, N. C. (2019). Immature platelet fraction as a useful marker in the etiological determination of thrombocytopenia. Experimental Hematology.

https://doi.org/10.1016/j.exphem.2019.09.001

\section{Published in:}

Experimental Hematology

Document Version:

Peer reviewed version

Queen's University Belfast - Research Portal:

Link to publication record in Queen's University Belfast Research Portal

Publisher rights

@2019 ISEH - Society for Hematology and Stem Cells.

This work is made available online in accordance with the publisher's policies. Please refer to any applicable terms of use of the publisher.

\section{General rights}

Copyright for the publications made accessible via the Queen's University Belfast Research Portal is retained by the author(s) and / or other copyright owners and it is a condition of accessing these publications that users recognise and abide by the legal requirements associated with these rights.

Take down policy

The Research Portal is Queen's institutional repository that provides access to Queen's research output. Every effort has been made to ensure that content in the Research Portal does not infringe any person's rights, or applicable UK laws. If you discover content in the Research Portal that you believe breaches copyright or violates any law, please contact openaccess@qub.ac.uk. 


\section{Abstract}

Background: The aetiology of thrombocytopenia is important in treatment and management of the condition. Most platelet parameters that are routinely analysed in the diagnostic laboratory have not proven useful in identifying the aetiology while specialised assays suffer from poor standardisation and lack of agreement between laboratories. The immature platelet fraction (IPF), which indirectly provides a measure of bone marrow function is showing promise as a valuable marker of thrombopoietic responses. Objectives: To determine whether the IPF could effectively identify specific underlying aetiologies of thrombocytopenia in a large thrombocytopenic cohort, to allow for quicker, more effective management of the condition. Patients and Methods: The IPF was analysed in a large cohort of 637 thrombocytopenic patients and 171 healthy control patients on the Sysmex XN 10 haematology analyser using the specialised fluorescence optical analysis. The thrombocytopenic patients were divided into six cohorts based on aetiology. Results: The IPF\%, was significantly higher in cases of increased platelet consumption (median=9.55, $\min =1.1$, $\max =77.9$ ), or pseudothrombocytopenia (median=13.1, $\min =0.4$, $\max =28.8$ ) compared with control (median=4.2, $\min =1.3, \max =12.8$ ). Furthermore, the IPF\% was also able to identify idiopathic thrombocytopenic purpura (ITP) $(P<0.05)$ (median=13.4, $\min =2.8$, $\max =77.9)$ from other causes of increased platelet consumptive disorders (Infection; median=6.4, $\min =1.1, \quad \max =21.6 ; \quad$ haemorrhage, median=8.9, $\min =1.2, \quad \max =20.2$ ). Conclusion: Using this large thrombocytopenic cohort, the IPF\% has been shown to be of significant diagnostic value, providing a useful rapid test in the aetiological investigation of platelet disorders. 
Keywords: Immature Platelet Fraction, Platelet, Thrombocytopenia, Idiopathic Thrombocytopenic Purpura, Aetiology

\section{Introduction}

Thrombocytopenia is a finding common to a number of underlying conditions [1-4]. Accurate identification of aetiology is critical to appropriate management of these patients. Thrombocytopenia is defined as a platelet count (PLT) below the $2.5^{\text {th }}$ percentile of a normal platelet distribution, with a concentration $<150 \times 10^{9} / \mathrm{L}$ in whole blood [5]. Yet clinically significant spontaneous bleeding does not usually occur until the PLT is $<10-20 \times 10^{9} / \mathrm{L}$. Bleeding episodes can occur at higher PLT in some patient groups, while in others, a lower PLT can be 'tolerated' [5]. This heterogeneity in patient tolerability adds to the difficulty in managing thrombocytopenia in the absence of a definitive cause and means that the PLT is not always relevant when considering severity and need for platelet transfusion.

The cause of thrombocytopenia can be broadly divided into three main categories: (i) reduced thrombopoiesis (ii) increased platelet destruction or consumption and (iii) abnormal distribution (sequestration) of platelets [6]. However, this can be an over-simplification; there are multiple causes of increased platelet consumption, such as infection, haemorrhage or immune destruction of platelets, each of which would be managed differently.

Full blood count (FBC) and blood films are used most frequently in the diagnosis of thrombocytopenia as they are cheap, easy to perform, and widely available. Specialised assays such as the Thrombopoietin ELISA, direct platelet immunofluorescence test [7] or drugdependent platelet antibody test [8] are used less often, suffering from poor standardisation and lack of agreement between laboratories [9]. 
A number of platelet parameters measured as part of the FBC such as mean platelet volume (MPV), platelet distribution width (PDW) and platelet-large cell ratio (P-LCR) have been reported to be useful in the investigation of thrombocytopenia. MPV was found to be significantly higher in 'hyperdestruction' thrombocytopenia than 'hypoproductive' thrombocytopenia [10], while both MPV and PDW have been reported be increased in Immune thrombocytopenic Purpura (ITP) $[11,12]$. However, these indices are vulnerable to changes in the platelet size/volume which can occur as an artefact between phlebotomy and sample analysis. Indeed, despite the potential for clinical utility evident from these studies, MPV, PDW and P-LCR have had limited use in clinical practice for thrombocytopenia investigation [13].

The immature platelet fraction (IPF), is analysed as part of the FBC and maybe useful as a rapid, cheap, reliable marker of thrombocytopenic aetiology. Immature platelets are those recently released from the bone marrow. They contain small amounts of RNA within the cytoplasm and are more reactive than mature platelets [14]. The number of circulating immature platelets reflects the rate of thrombopoiesis and bone marrow function, and as such, may be useful in the determination of thrombocytopenic aetiology [15].

Increased IPF has previously been found in some platelet destruction or consumption disorders and highlights the thrombopoietic response from the bone marrow [16]. IPF has also been shown to be reduced in bone marrow failure cases [16]. However, the majority of published work concentrates on IPF in a small selection of specific disorders (e.g. ITP or following stem cell transplantation). Research looking at larger thrombocytopenic cohorts with a wider range of underlying conditions is warranted. The present study, which included a large sample $(n=637)$ of thrombocytopenic patient samples with varying underlying causes, 
aimed to determine whether the IPF, has potential to be used as a maker in the aetiological determination of thrombocytopenia.

\section{Methods}

\section{Study Overview}

The study was performed at Airedale General Hospital (AGH) Haematology department (Steeton, UK). Local ethical approval from the AGH research governance department was granted. Ethical approval from National Research Ethics Service (NRES) was not required as all samples were being taken as part of the routine diagnostic work-up. Blood samples for FBC were received from 34 hospital wards and 67 general practitioner practices from West \& North Yorkshire as part of their investigations. A total of 637 patients were identified as thrombocytopenic (platelet count $<140 \times 10^{9} / \mathrm{L}$, based on AGH reference range). Male and female patients were accepted into the study and there was no exclusion criteria regarding age. Any patient that had received a platelet transfusion within the previous thirty days was excluded. A control group consisting of 171 patients was identified. These patients were preoperative patients at $\mathrm{AGH}$ who had blood samples taken as part of the normal hospital surgical protocols and were tested for full blood count and IPF. All FBC parameters were inside the reference ranges and no transfusion history within the previous thirty days.

\section{Sample Collection}

Blood samples were collected into $4 \mathrm{ml}$ (K2) EDTA vacutainers (Becton Dickinson). All samples were kept at room temperature $\left(18-25^{\circ} \mathrm{C}\right)$ until testing, as at colder storage temperatures the IPF\% rises leading to false results [17]. All samples were processed within six hours from venepuncture, a timeframe validated in previous studies [18]. As previously mentioned, 
although it has been demonstrated that mean platelet volume (MPV) analysis is time-critical and should preferably be performed within two hours of venpuncture due to platelet swelling [19], IPF analysis is based on oxazine staining which specifically stains platelet RNA [20] and is therefore significantly less vulnerable to the effects of platelet size.

IPF Analysis

Blood samples were processed for FBC on the Sysmex XN 10 haematology analysers as part of the XN 9000 system, (Sysmex Corporation, Kobe, Japan) in whole blood mode. Both platelet impedence (PLT-I) and fluorescence platelet count (PLT-F) were analysed. The PLT-F provides an accurate platelet count in thrombocytopenic patients using fluorescence flow cytometry. As part of the platelet-F count, an accurate measure of IPF is calculated. The haematology Sysmex XN 10 analyser was calibrated and then quality controlled every 24 hours using XN CHECK L2 (Sysmex Corporation, Kobe, Japan).

Data handling and Statistical Analysis.

Statistical analyses were performed using GraphPad Prism software, version 5. D'Agostino \& Pearson omnibus test was used to test for normality. The PLT and IPF\% for control males, and control females were found to be normally distributed. For non-parametric data (all thrombocytopenic cohorts), Kruskal-Wallis analysis was employed with Dunn's post-hoc testing, and $P$ values of $<0.05$ were considered statistically significant.

\section{Results and Discussion}

As expected, there was a significant difference $(P<0.05)$ in the PLT between males and females (data not shown). Males and females were therefore initially treated as two separate groups 
when considering the PLT for the thrombocytopenic cohorts. However following further analysis, it was noted that the data trends and statistical differences between aetiological groups within each gender group were identical so the PLT data were combined and discussed as one. The data for males and females were also treated as a single entity when considering the IPF\%. The normal reference range established in the present study was $1.3-12.8 \%$, which was in keeping with that derived by Ali et al. (2017) [21]. However Ali et al. did report on small but significant differences in IPF\% between healthy males and females, and therefore derived two separate reference ranges. The reason for the different findings between studies may simply be down to sample size, with the present study deriving the reference range from 171 controls, while Ali et al. derived from a control population of 2366 [21].

The thrombocytopenic data were initially grouped into three general aetiologies (i) reduced thrombopoiesis, (ii) increased platelet destruction or consumption, and (iii) abnormal distribution (sequestration) of platelets. By definition, all aetiological groups were shown to have a significantly lower PLT than the control group (Table 1). However, as expected, and shown in similar studies [22], the three thrombocytopenic cohorts could not be discriminated by the PLT (Figure 1A). The IPF was considered in these same three thrombocytopenic cohorts. The IPF\% parameter was chosen for this study instead of the absolute IPF count (IPF \#) because it has been shown to correlate better with megakaryopoiesis and thrombopoiesis than IPF\# in various congenital and acquired disorders with the exception of ALL [23]. As expected, and in agreement with other studies [24,25], analysis of the IPF\% in normal samples $(n=171)$ and all thrombocytopenic patients $(n=637)$ (Table 1$)$ demonstrated a significantly higher IPF\% in thrombocytopenia than in the control group, and this was also the case when 
comparing cohorts within a specific gender. This justified further investigation into the parameter to clarify its usefulness as a marker of specific underlying causes of thrombocytopenia.

Comparison of IPF\% in the three aetiological groups revealed significant differences between the reduced thrombopoiesis and increased consumption group $(P<0.01)$, and the increased consumption group and the abnormal distribution group $(P<0.01)$. The high values observed in increased consumption allowed effective discrimination of this aetiological group thereby showing the usefulness of the IPF\% in this setting.

The data were further sub-divided into the six thrombocytopenic cohorts stated in Table 1. The median IPF\% were compared to determine significant differences between the groups (Figure 2A). Surprisingly, the most notable group to be differentiated was the pseudothrombocytopenia group which showed significantly higher IPF\% than all other groups, highlighting the usefulness of this marker in identifying possible aetiology. The high IPF\% in pseudothrombocytopenia is an interesting finding. In this case, the elevated value is not reflective of an increased thrombopoietic response but rather an artefactual effect of platelet size or platelet aggregation [26]. As mentioned earlier, IPF\% should be less vulnerable to sample artefacts, from use of EDTA and also delays in sample analysis, than MPV or PDW analysis. However there will still be some degree of interference. Yet, when considering the utility of a new parameter, one must consider the feasibility of analysis in a high workload environment in standard sample types. The results presented here demonstrate the usefulness of IPF\% analysis in standard EDTA samples measured in a timeframe that is achievable in a diagnostic haematology laboratory. 
The increased consumption group was also easy to differentiate from other cohorts, showing a significantly higher median than four out of five aetiological groups. Indeed, patients with increased platelet consumption were found to have a significantly higher IPF\% than patients with reduced thrombopoiesis, drug-related thrombocytopenia, platelet sequestration (abnormal distribution) and pseudothrombocytopenia. The value of IPF\% was not as useful when differentiating other groups; the reduced thrombopoiesis group could be separated from two groups (increased consumption and pseudothrombocytopenia), however, it could not be differentiated from drug-related thrombocytopenia, platelet sequestration, or thrombocytopenia of unidentified aetiology. Furthermore, the drug and splenic sequestration groups could not be differentiated from each other by IPF\% (Figure 2A).

The thrombocytopenic cohorts were further split into the underlying conditions causing the platelet pathology in these patients (see Table 1, footnote). The increased consumption group was sub-divided into infection, ITP and haemorrhage. It is expected that patients with infection would show an increased IPF\%, since the resulting platelet activation from bacterial invasion results in adhesion of platelets to other immune cells or to thrombus formation, which in-turn leads to a consumptive state. More than $50 \%$ of sepsis patients develop a low platelet count, ranging from a mild decrease to severe thrombocytopenia and the degree of thrombocytopenia can be used to predict mortality in sepsis [27]. Increased IPF\% would also be expected in cases of haemorrhage, due to increased thrombopoiesis as a response to platelet consumption to limit blood loss. However, elevated IPF\% is not always seen in haemorrhage patients and is dependent upon the time of testing in relation to active 
bleeding. Naturally, there will be a delay between active bleeding and the thrombopoietic response [28], and this time period will be dependent upon the reserve pool of platelets which will be released to cover the depletion. Yet, it was the ITP sub-group that showed the highest IPF\%, and this allowed differentiation of ITP from the other two aetiologies (infection $P<0.001$ and haemorrhages $P<0.05)$. Indeed, the highest IPF\% recorded in this study was in a sample from a patient with ITP (77.9\%). However, the IPF\% is not universally elevated in ITP. If the ITP autoantibodies affect the bone marrow in ITP, it follows that the IPF will not be as high when compared with cases in which the autoantibodies have not reached the bone marrow [29]. The results however, do demonstrate the power of IPF\% as a differential indicator of ITP when infection and haemorrhage have not yet been ruled out during the investigative process. In similar studies, higher IPF\% values were observed in both ITP compared to reduced thrombopoeitic disorders [22,25], and these studies also focused on EDTA-anticoagulated samples. Ferriera et al. were also able to demonstrate that the IPF\% was significantly higher still in patients with hereditary macrothrombocytopenia, again demonstrating the usefulness of this parameter in differential diagnosis.

When the reduced thrombopoiesis, drug-related thrombocytopenia, abnormal distribution and pseudothrombocytopenia groups were further sub-divided, there were no significant differences in IPF\% between the underlying pathologies within these groups (data not shown). The IPF\% in the drug-related group was relatively low in comparison with the other groups. Further sub-dividing the data based on drug-type (chemotherapy, methotrexate sulfasalazine and antibiotics) did not show any significant findings. Chemotherapy drugs can destroy the megakaryocytic progenitors at the beginning of differentiation preventing 
immature platelet production, which explains the lower IPF values [30,31]. Although some antibiotics have also been shown to cause thrombocytopenia, this response is not seen in all patients on the same drug [32], and the underlying infection plays a bigger role in the thrombocytopenia in most patients than the antibiotic itself. As the mechanisms involved in drug-induced thrombocytopenias are varied with some affecting the bone marrow and others not, the IPF\% cannot be used to separate or diagnose the aetiology of drug-related thrombocytopenia. The abnormal distribution group had only seven results out of a total of sixty-four that were above normal ranges. The multiple disorders that involve splenic sequestration of platelets as a secondary consequence may also affect the bone marrow in a large majority of patients, resulting in normal IPF\% values, in a setting that should promote thrombopoiesis [33].

The data obtained in this study, significantly expand on that of similar studies reporting on smaller thrombocytopenic sample sizes with fewer underlying aetiologies [34,35]. The present study provides solid evidence that the IPF\% can allow the separation of increased consumption disorders especially ITP. The aetiology of thrombocytopenia is important in treatment and management of the condition. Therefore, increasing inclusion of this marker in the hospital diagnostic testing panel and standardisation of defined ranges, will have significant impact on time taken to identify the underlying cause of thrombocytopenia and allow for effective treatment/management of thrombocytopenic patients. 
References:

[1] Venkata, C., Kashyap, R., Farmer, J. C., \& Afessa, B. (2013). Thrombocytopenia in adult patients with sepsis: incidence, risk factors, and its association with clinical outcome. Journal of intensive care. $1(1): 9$

[2] Dahal, S., Upadhyay, S., Banjade, R., Dhakal, P., Khanal, N., \& Bhatt, V. R. (2017). Thrombocytopenia in Patients with Chronic Hepatitis C Virus Infection. Mediterranean journal of hematology and infectious diseases. 9(1): e2017019

[3] Townsley, D. M., Desmond, R., Dunbar, C. E., \& Young, N. S. (2013). Pathophysiology and management of thrombocytopenia in bone marrow failure: possible clinical applications of TPO receptor agonists in aplastic anemia and myelodysplastic syndromes. International journal of hematology. 98(1): 48-55.

[4] Mitchell, O., Feldman, D. M., Diakow, M., \& Sigal, S. H. (2016). The pathophysiology of thrombocytopenia in chronic liver disease. Hepatic medicine : evidence and research. 8:3950.

[5] Stasi, R. (2012). How to approach thrombocytopenias. Hematology. 2012: 191-197.

[6] Izak, M., \& Bussel, J. B. (2014). Management of thrombocytopenia. F1000prime reports. 6:45.

[7] British Committee for Standards in Haematology. (2003). Guidelines for the investigation and management of idiopathic thrombocytopenic purpura in adults, children and in pregnancy. British Journal of Haematology. 120(4): 574-596.

[8] Smock, K.J. \& Perkins, S.L. (2014). Thrombocytopenia: An update. International Journal of Laboratory Hematology. 36(3):269-278. 
[9] Gresele, P., Harrison, P., Bury, L., Falcinelli, E., Gachet, C., Hayward, C. P., Kenny, D., Mezzano, D., Mumford, A. D., Nugent, D., Nurden, A. T., Orsini, S. and Cattaneo, M. (2014). Diagnosis of suspected inherited platelet function disorders: results of a worldwide survey. Journal Of Thrombosis And Haemostasis. 12(9)1562-1569.

[10] Numbenjapon, T., Mahapo., N, Pornvipavee, R., Sriswasdi, C., Mongkonsritragoon, W., Leelasiri, A. \& Prayoonwiwat W. (2008). A prospective evaluation of normal mean platelet volume in discriminating hyperdestructive thrombocytopenia from hypoproductive thrombocytopenia. International Journal of Laboratory Hematology.30(5):408-14

[11] Ntaios, G., Papadopoulos, A., Chatzinikolaou, A., Saouli, Z., Karalazou, P., Kaiafa, G., Girtovitis, F., Kontoninas, Z., Savopoulos, C., Hatzitolios, A. \& Alexiou-Daniel, S. (2008). Increased values of mean platelet volume and platelet size deviation width may provide a safe positive diagnosis of idiopathic thrombocytopenic purpura. Acta Haematologica. 119(3):173-7)

[12] Kaito, K., Otsubo, H., Usui, N., Yoshida, M., Tanno, J., Kurihara, E., Matsumoto, K., Hirata, R., Domitsu, K., \& Kobayashi, M. (2005). Platelet size deviation width, platelet large cell ratio, and mean platelet volume have sufficient sensitivity and specificity in the diagnosis of immune thrombocytopenia. British Journal of Haematology. 128(5):698-702

[13] Leader A, Pereg D, Lishner M. (2012). Are platelet volume indices of clinical use? A multidisciplinary review. Annals of Medicine. 44(8):805-16

[14] Briggs, C. (2009). Quality counts: new parameters in blood cell counting. International Journal Of Laboratory Hematology. 31(3):277-297.

[15] Dusse, L.M. and Freitas, L.G. (2015). Clinical applicability of reticulated platelets. Clinica Chimica Acta. 15;439:143-7.

[16] Hoffmann, J. J. M. L. (2014) Reticulated platelets: analytical aspects and clinical utility. Clinical Chemistry And Laboratory Medicine. 52(8)1107-1117. 
[17] Osei-Bimpong, A., Saleh, M., Sola-Visner, M., Widness, J. and Veng-Pedersen, P. (2010). Correction for effect of cold storage on immature platelet fraction. Journal of Clinical Laboratory Analysis.24(6):431-433.

[18] Ruisi, M. M., Psaila, B., Ward, M. J., Villarica, G. and Bussel, J. B. (2010). Stability of measurement of the immature platelet fraction. American Journal Of Hematology. 85(8)622624.

[19] Endler, G., Klimesch, A., Sunder-Plassmann, H., Schillinger, M., Exner, M., Mannhalter, C., Jordanova, N., Christ, G., Thalhammer, R., Huber, K. \& Sunder-Plassmann, R. (2002). Mean platelet volume is an independent risk factor for myocardial infarction but not for coronary artery disease. British Journal of Haematology. 117: 399-404

[20] Wada, A., Takagi, Y., Kono, M. and Morikawa, T. (2015). Accuracy of a new platelet count system (PLT-F) depends on the staining property of its reagents. PLOS ONE, 10(10):e0141311

[21] Ali, U., Knight, G., Gibbs, R. \& Tsitsikas, D.A. (2017). Reference intervals for absolute and percentage immature platelet fraction using the Sysmex XN-10 automated haematology analyser in a UK population. Scandinavian Journal of Clinical and Laboratory Investigation. $77(8): 658-664$

[22] Ferreira, F.L.B., Colella, M.P., Medina, S.S., Costa-Lima, C., Fiusa, M.M.L., Costa, L.N.G., Orsi, F.A., Annichino-Bizzacchi, J.M., Fertrin, K.Y., Gilberti, M.F.P., Ozelo, M.C. \& De Paula, E.V. (2017). Evaluation of the immature platelet fraction contribute to the differential diagnosis of hereditary, immune and other acquired thrombocytopenias. Scientific Reports. 7:3355

[23] Stasi, R., Amadori, S., Osborn, J., Newland, A. C. and Provan, D. (2006). Long-term outcome of otherwise healthy individuals with incidentally discovered borderline thrombocytopenia. Plos Medicine. 3(3):e24-e24. 
[24] Bhat, R. \& Pai, S. (2015). Immature Platelet Fraction: A Platelet Parameter With Significant Clinical Utility. American Journal of Clinical Pathology.144(2)A142.

[25] Cybulska, A., Meintker, L., Ringwald, J. \& Krause, S.W. (2017). Measurements of immature platelets with haematology analysers are of limited value to separate immune thrombocytopenia from bone marrow failure. British Journal of Haematology. 177, 612-619

[26] Miyazaki, K., Koike, Y., Kunishima, S., Ishii, R., Danbara, M., Horie, R., Yatomi, Y. and Higashihara, M. (2015). Immature platelet fraction measurement is influenced by platelet size and is a useful parameter for discrimination of macrothrombocytopenia. Hematology. 20(10):587-592.

[27] Koyama, K., Katayama, S., Muronoi, T., Tonai, K., Goto, Y., Koinuma, T., Shima, J., Nunomiya, S. (2018). Time course of immature platelet count and its relation to thrombocytopenia and mortality in patients with sepsis. PloS one. 13(1):e0192064.

[28] Bride, K.L., Lim, D., Paessler, M. \& Lambert, M.P. (2015). Can Immature Platelet Fraction (IPF) be Used to Assess Bleeding Risk in Pediatric Immune Thrombocytopenia (ITP) and to Differentiate ITP from Bone Marrow Failure/Aplastic Anemia? A Retrospective Analysis. Blood. 126:3474.

[29] Briggs, C., Kunka, S., Hart, D., Oguni, S. and Machin, S. J. (2004). Assessment of an immature platelet fraction (IPF) in peripheral thrombocytopenia. British Journal of Haematology. 126(1):93-99.

[30] Zeuner, A., Signore, M., Martinetti, D., Bartucci, M., Peschle, C. and De Maria, R. (2007). Chemotherapy-induced thrombocytopenia derives from the selective death of megakaryocyte progenitors and can be rescued by stem cell factor. Cancer Research. 67(10):4767-4773. 
[31] Wu, Y., Aravind, S., Ranganathan, G., Martin, A. and Nalysnyk, L. (2009). Anemia and thrombocytopenia in patients undergoing chemotherapy for solid tumors: a descriptive study of a large outpatient oncology practice database, 2000-2007. Clinical Therapeutics. 31(2):2416-2432 .

[32] Johansen, M. E., Jensen, J.-U., Bestle, M. H., Hein, L., Lauritsen, A. Ф., Tousi, H., Larsen, K. M., Løken, J., Mohr, T., Thormar, K., Johansson, P. I., Cozzi-Lepri, A. and Lundgren, J. D. (2013). The potential of antimicrobials to induce thrombocytopenia in critically ill patients: data from a randomized controlled trial. Plos One. 8(11) e81477-e81477.

[33] Hayashi, H., Beppu, T., Shirabe, K., Maehara, Y. and Baba, H. (2014). Management of thrombocytopenia due to liver cirrhosis: a review. World Journal Of Gastroenterology. 20(10):2595-2605.

[34] Pons, I., Monteagudo, M., Lucchetti, G., Muñoz, L., Perea, G., Colomina, I., Guiu, J. and Obiols, J. (2010). Correlation between immature platelet fraction and reticulated platelets. Usefulness in the etiology diagnosis of thrombocytopenia. European Journal Of Haematology. $85(2): 158-163$

[35] Monteagudo, M., Amengual, M. J., Muñoz, L., Soler, J. A., Roig, I. and Tolosa, C. (2008). Reticulated platelets as a screening test to identify thrombocytopenia aetiology. QJM: Monthly Journal Of The Association Of Physicians.101(7): 549-555 


\section{Figure and Table Legends}

Table 1: Patient clinical and laboratory data.

Figure 1: Ability of (A) Platelet count (PLT) and (B) Immature Platelet Fraction (IPF\%) to differentiate between three thrombocytopenic cohorts (RT: Reduced thrombopoiesis, IC: Increased consumption, AD: Abnormal Distribution). Statistical analysis was performed using the Kruskal-Wallis test with Dunn's post-hoc analyses. Data are presented as median \pm range. Statistical significance between each of the groups is shown in the tables in the lower part of the figure.

Figure 2: (A) Differentiation of six thrombocytopenic cohorts, and (B) further differentiation of the underlying mechanism responsible for the increased platelet consumption, by analysis of Immature Platelet Fraction (IPF\%). (RT: Reduced thrombopoiesis, IC: Increased consumption, AD: Abnormal Distribution (included Alcohol-related Liver Disease, hepatitis infections, portal hypertension DR: Drug-related, AD: Abnormal Distribution, PS: Pseudothrombocytopenia, UA: Unidentified aetiology, ITP: Idiopathic Thrombocytopenic Purpura). Statistical analysis was performed using the Kruskal-Wallis test with Dunn's posthoc analyses. Data are presented as median \pm range. Statistical significance between each of the groups is shown in the tables in the lower part of the figure. 


\section{Addendum}

All the authors contributed to the analysis and/or interpretation of data, and to the revision of the intellectual content of the manuscript. All the authors gave their approval to the final version of the manuscript. C Graham had substantial contribution to the design of the study. N Dempsey-Hibbert drafted the manuscript. I Ali was responsible for the recruitment of the samples and sample analysis. All authors contrinuted to the data handling and statistical analysis.

\section{Declaration of Interest statement}

None to declare. 

A

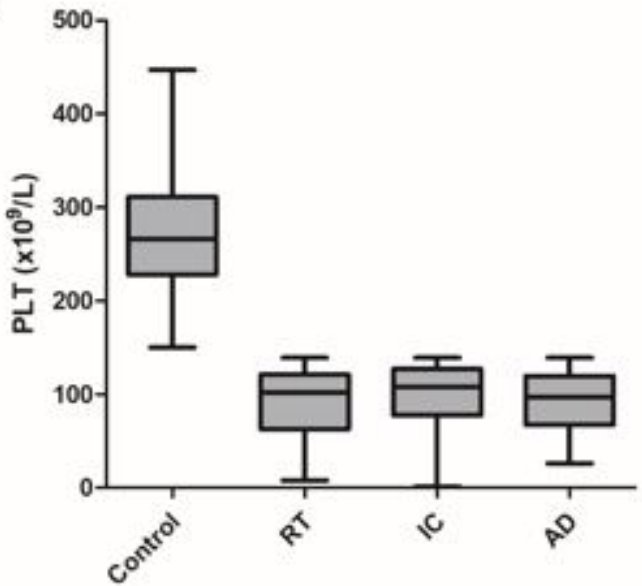

\begin{tabular}{|c|c|c|c|c|}
\hline & Control & RT & IC & $\mathrm{AD}$ \\
\hline \multicolumn{4}{|c|}{ Control } & \\
\hline RT & $P<0.001$ & & & \\
\hline IC & $P<0.001$ & n.s & & \\
\hline$A D$ & $p<0,001$ & n.s & n.s & \\
\hline
\end{tabular}


B

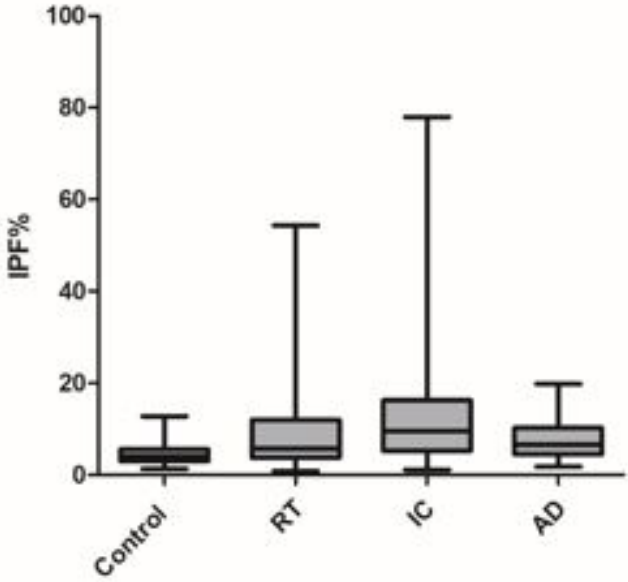

\begin{tabular}{|l|l|l|l|l|}
\hline & Control & RT & IC & AD \\
\hline Control & \multicolumn{3}{|l}{} \\
\cline { 1 - 3 } RT & P $<0.001$ & \multicolumn{3}{|l}{} \\
\cline { 1 - 3 } IC & P $<0.001$ & P $<0.01$ & \\
\hline AD & P $<0.001$ & n.s & P $<0.01$ & \\
\cline { 1 - 3 }
\end{tabular}




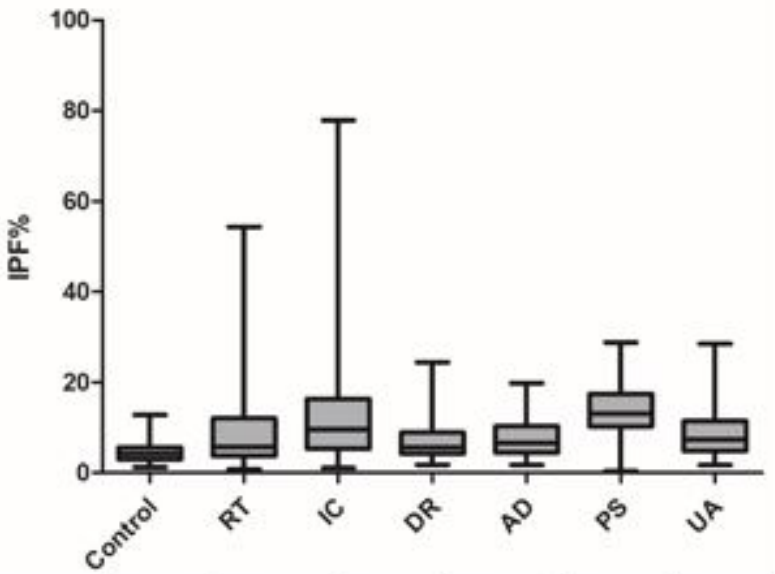

\begin{tabular}{|c|c|c|c|c|c|c|c|}
\hline & Control & RT & IC & DR & $A D$ & PS & UA \\
\hline \multicolumn{8}{|c|}{ Control } \\
\hline RT & P $<0,001$ & & & & & & \\
\hline IC & $P<0,001$ & $P<0.05$ & & & & & \\
\hline DR & D<0.01 & n.5 & $p<0.01$ & & & & \\
\hline $\mathrm{AD}$ & PC0.001 & 0.5 & $P 00.05$ & ns & & & \\
\hline DS & $p<0.001$ & $p<0.001$ & $P<0.01$ & $D \times 0.001$ & $p<0.001$ & & \\
\hline UA & $p<0.001$ & n.s & n.s & n.s & $\mathrm{n}, \mathrm{s}$ & $p<0.001$ & \\
\hline
\end{tabular}




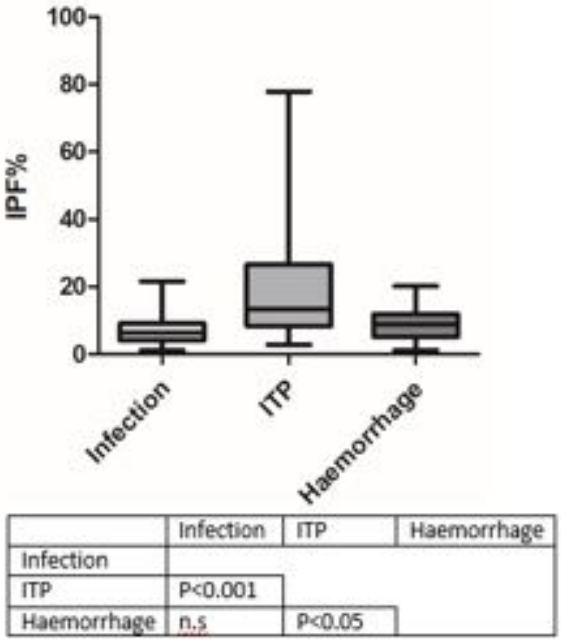


Table 1: Patient clinical and laboratory data.

\begin{tabular}{|c|c|c|c|c|c|c|}
\hline Groups & Sex & $\begin{array}{c}\text { Sample } \\
\text { size } \\
\text { (n) }\end{array}$ & $\begin{array}{l}\text { Mean age } \\
\text { (SD) }\end{array}$ & Age range & $\begin{array}{c}\text { Median } \\
\text { PLT }\left(\times 10^{9} / \mathrm{L}\right) \\
\text { (Range) }\end{array}$ & $\begin{array}{c}\text { Median IPF\% } \\
\text { (Range) }\end{array}$ \\
\hline \multirow[t]{2}{*}{ Reduced Thrombopoiesis $^{1}$} & Male & 55 & $\begin{array}{c}72.89 \\
(16.87)\end{array}$ & $15-95$ & $\begin{array}{c}100 \\
(8-139)\end{array}$ & $\begin{array}{c}5.75 \\
(0.8-39.1)\end{array}$ \\
\hline & Female & 21 & $\begin{array}{c}78.00 \\
(13.45)\end{array}$ & $46-92$ & $\begin{array}{c}104 \\
(9-134)\end{array}$ & $\begin{array}{c}5.25 \\
(1.4-54.3)\end{array}$ \\
\hline \multirow[t]{2}{*}{ Increased Consumption ${ }^{2}$} & Male & 51 & $\begin{array}{c}66.02 \\
(25.87)\end{array}$ & $1-92$ & $\begin{array}{c}96 \\
(1-138)\end{array}$ & $\begin{array}{c}8.9 \\
(1.1-36.4) \\
\end{array}$ \\
\hline & Female & 71 & $\begin{array}{c}56.82 \\
(25.26)\end{array}$ & $6-96$ & $\begin{array}{c}112 \\
(1-139)\end{array}$ & $\begin{array}{c}9.7 \\
(2.1-77.9)\end{array}$ \\
\hline \multirow[t]{2}{*}{ Drugs $^{3}$} & Male & 31 & $\begin{array}{l}72.32 \\
(8.56)\end{array}$ & $51-89$ & $\begin{array}{c}101 \\
(16-137)\end{array}$ & $\begin{array}{c}6.4 \\
(2.9-23.1)\end{array}$ \\
\hline & Female & 34 & $\begin{array}{c}66.12 \\
(13.98)\end{array}$ & $27-87$ & $\begin{array}{c}98.5 \\
(4-138)\end{array}$ & $\begin{array}{c}5.25 \\
(1.8-24.4)\end{array}$ \\
\hline \multirow[t]{2}{*}{$\begin{array}{l}\text { Abnormal Distribution } \\
\text { (Splenic Sequestration) }^{4}\end{array}$} & Male & 39 & $\begin{array}{c}54.54 \\
(12.49)\end{array}$ & $31-83$ & $\begin{array}{c}99 \\
(26-138)\end{array}$ & $\begin{array}{c}6.9 \\
(2-19.8) \\
\end{array}$ \\
\hline & Female & 25 & $\begin{array}{c}56.28 \\
(13.64)\end{array}$ & $35-82$ & $\begin{array}{c}97 \\
(44-139)\end{array}$ & $\begin{array}{c}5.3 \\
(1.8-14.8)\end{array}$ \\
\hline \multirow[t]{2}{*}{ Pseudothrombocytopenia $^{5}$} & Male & 83 & $\begin{array}{c}62.54 \\
(19.78)\end{array}$ & $1-91$ & $\begin{array}{c}83 \\
(10-138)\end{array}$ & $\begin{array}{c}13.3 \\
(0.2-28.8)\end{array}$ \\
\hline & Female & 94 & $\begin{array}{c}56.78 \\
(21.86)\end{array}$ & $1-90$ & $\begin{array}{c}94.5 \\
(1-137)\end{array}$ & $\begin{array}{c}12.8 \\
(1.9-28.0)\end{array}$ \\
\hline \multirow[t]{2}{*}{ Unidentified Aetiology ${ }^{6}$} & Male & 83 & $\begin{array}{c}67.83 \\
(17.93)\end{array}$ & $1-95$ & $\begin{array}{c}117 \\
(22-139)\end{array}$ & $\begin{array}{c}8.8 \\
(1.7-28.5)\end{array}$ \\
\hline & Female & 50 & $\begin{array}{c}61.48 \\
(23.63)\end{array}$ & $1-100$ & $\begin{array}{c}117.5 \\
(47-137)\end{array}$ & $\begin{array}{c}6.6 \\
(2.7-26.2)\end{array}$ \\
\hline \multirow[t]{2}{*}{ Normal Control } & Male & 72 & $\begin{array}{c}62.44 \\
(14.73)\end{array}$ & $21-84$ & $\begin{array}{c}239.5 \\
(150-365)\end{array}$ & $\begin{array}{c}4.5 \\
(1.3-12.8)\end{array}$ \\
\hline & Female & 99 & $\begin{array}{c}56.54 \\
(16.88)\end{array}$ & $25-85$ & $\begin{array}{c}286 \\
(179-447)\end{array}$ & $\begin{array}{c}4.2 \\
(1.4-10.7)\end{array}$ \\
\hline
\end{tabular}

SD: Standard Deviation. PLT = Platelet Count. IPF = Immature Platelet Fraction.

${ }^{1}$ Includes any disorder that affects thrombopoiesis, (e.g. Chronic Lymphocytic Leukaemia, Acute Myeloid Leukaemia, Myelodysplastic Syndrome, Chronic Myelomonocytic Leukaemia, Lymphoma, Megaloblastic Anaemia).

${ }^{2}$ Includes any disorder that resulted in consumption or destruction of platelets (infections, immune thrombocytopenic purpura, haemorrhage).

${ }^{3}$ Includes any thrombocytopenia directly caused by administration of a medication (Chemotherapy, Methotrexate, Sulphalasazine, Antibiotic).

${ }^{4}$ Splenic sequestration group had disorders that resulted in platelet pooling as part of the mechanism of thrombocytopenia (Alcoholrelated liver disease, hepatitis, portal hypertension)

${ }^{5}$ Includes any disorder that showed a low numerical platelet count but was identified as normal from a blood smear (Platelet clumps, Platelet clots, Satellitism)

${ }^{6}$ Includes thrombocytopenic cases where no cause can be identified. 
Highlights:

- Determination of aetiology is critical for correct management of thrombocytopenia

- Immature Platelet Fraction (IPF) can act as an indicator of thrombopoietic response

- Ability of IPF to verify aetiology in a large cohort of patients was assessed

- IPF was effective in identifying ITP and pseudothrombocytopenia from other causes 